\title{
Chitosan-Based Thermo-Responsive Scaffold for Wound Healing Provides Dexketoprofen Trometamol Controlled Release for 24 Hour-Use
}

\author{
Luis Castillo-Henríquez ${ }^{1,2}$, Pablo Sanabria-Espinoza ${ }^{2}$, Brayan Murillo-Castillo², Gabriela Montes de Oca-Vásquez ${ }^{1}$, \\ Diego Batista-Menezes', Briner Calvo-Guzmán², Nils Ramírez-Arguedas',4, José Vega-Baudrit ${ }^{1,5, *}$ \\ 1 National Laboratory of Nanotechnology (LANOTEC), National Center for High Technology (CeNAT), 1174- \\ 1200, San José, Costa Rica; luis.castillohenriquez@ucr.ac.cr (L.C.H); gmontesdeoca@cenat.ac.cr (G.M.V); \\ dbatista@cenat.ac.cr (D.B.M) \\ 2 Laboratory of Physical Chemistry, Faculty of Pharmacy, University of Costa Rica, 11501-2060, San José, Costa \\ Rica; pablo.sanabriaespinoza@ucr.ac.cr (P.S.E); brayan.murillocastillo@ucr.ac.cr (B.M.C) \\ 3 Laboratorios Infarma LTDA, 30801, Cartago, Costa Rica; investigacionydesarrollo@laboratorioinfarma.com \\ (B.C.G) \\ 4 Laboratory of Biopharmacy and Pharmacokinetics (LABIOFAR), Institute of Pharmaceutical Research (IN- \\ IFAR) 11501-2060, San José, Costa Rica; nils.ramirez@ucr.ac.cr (N.R.A) \\ 5 Laboratory of Polymers (POLIUNA), Chemistry School, National University of Costa Rica, 86-3000, Heredia, \\ Costa Rica \\ * Correspondence: jvegab@gmail.com
}

\begin{abstract}
Chronic and non-healing wounds demand personalized and more effective therapies for treating complications and improve patient adherence. This work aims to develop a suitable chitosan-based scaffold to provide 24 hours controlled release of DKT, by taking advantage of chitosan's thermo-responsive behavior as well as local hyperthermia in wounds. Three formulation prototypes were developed using chitosan (F1), 2:1 chitosan: PVA (F2), and 1:1 chitosan:gelatin (F3). Compatibility tests were done by DSC, TG, and IR spectroscopy. SEM was employed to examine the morphology of the surface and inner layers from the scaffolds. In vitro release studies were performed at $32{ }^{\circ} \mathrm{C}$ and $38{ }^{\circ} \mathrm{C}$ to evaluate the release profiles, which were later adjusted to different kinetic models for the best formulation. F3 showed the most controlled release of DKT at $32{ }^{\circ} \mathrm{C}$ for 24 hours $(77.75 \pm 2.72 \%)$, and reduced the burst release in the initial 6 hours $(40.18 \pm 1.00 \%$ ), while at $38{ }^{\circ} \mathrm{C}$ the release reached $88.52 \pm 2.07 \%$ at 12 hours. The release profile for this formulation fits with Hixson-Crowell and Korsmeyer-Peppas kinetic models at both temperatures. Therefore, the developed chitosan/gelatin thermo-responsive scaffold provides a suitable system for wound healing with a controlled release of DKT for 24 hour-use, which can overcome adherence issues and wound complications.
\end{abstract}

Keywords: Chitosan; dexketoprofen trometamol; drug delivery; gelatin; NSAIDs; personalized medicine; smart polymers

\section{Introduction}

Wound healing involves coagulation, inflammation, epithelization, proliferation, and remodeling [1]. The early inflammatory process is characterized by five classical symptoms: redness, swelling, heat, pain, and loss of tissue function [2]. Moreover, chronic and non-healing wounds caused by different diseases (e.g., diabetes) demand special therapies for treating chronic inflammatory processes, infections and poor tissue regeneration [3]. Despite current interventions, there is a growing demand for personalized and more effective therapies for healing wounds that improve drug delivery, life quality, and patient adherence to the treatment [4]. 
Scaffolds composed of thermo-responsive polymers are excellent options for wound healing. These structures provide physical support that reproduces an extracellular matrix environment, enhancing tissue regeneration and cell growth [5,6]. Also, they represent an outstanding alternative for developing drug delivery systems due to the amphiphilic nature of the polymers and the ease of tuning their physicochemical properties $[7,8]$. A relevant property is the critical solution temperature (i.e., the temperature at which exists a balance in the competition between hydrophilic and hydrophobic polymer chains), which defines the volume phase transition suffered by these polymers, being classified as lower (LCST) -or upper critical solution temperature (UCST) [9].

Chitosan or $\beta$-(1-4)-2-amino-2-deoxy-D-glucopyranose, a chitin derivative, is a promising thermo-responsive polymer for wound healing with interesting properties that can vary according to the degree of deacetylation (i.e., the number of N-glucosamine units) but in general, it exhibits a LCST around $32{ }^{\circ} \mathrm{C}$ [10]. The polymer's easy processability into hydrogels and scaffolds make it suitable for the development of drug delivery systems loaded with non-steroidal anti-inflammatory drugs (NSAIDs) [11]. NSAIDs reversibly inhibit the cyclooxygenase (COX) enzyme, thereby reducing the levels of prostaglandins, allowing the treatment of acute and chronic inflammation, pain, fever and wound healing [12].

Dexketoprofen (DK) -a non-selective COX inhibitor- is the (S)-(+)-enantiomer of ketoprofen. It is used for the rapid management of mild to moderate pain with a maximum daily dose of $75 \mathrm{mg}$, administered as the tromethamine salt derivate, Dexketoprofen trometamol (DKT), that is a class 1 drug (i.e., high solubility and high permeability) according to the Biopharmaceutical Classification System (BCS) [13]. Different approaches to the delivery of DKT have been made, especially for the development of oral formulations $[14,15]$. However, little research has been reported for transdermal delivery, where none include the use of chitosan [16].

Therefore, this work aims to develop a suitable chitosan-based scaffold to provide 24 hours controlled release of DKT for wound healing. Compatibility tests were done by thermal analysis and infrared spectroscopy (IR) to assess physicochemical interactions between the components of the prototype formulations. Scanning Electron Microscopy (SEM) was employed to examine the morphology of the surface and inner layers of the scaffolds. Additionally, in vitro release studies were performed at $32{ }^{\circ} \mathrm{C}$ and $38^{\circ} \mathrm{C}$ to evaluate the release profiles, which were later adjusted to zero order, first order, HixsonCrowell, Higuchi, and Korsmeyer-Peppas kinetic models for the best formulation.

To our knowledge, no other paper describes a transdermal drug delivery system, consisting of a thermo-responsive chitosan-based scaffold loaded with DKT for wound healing and inflammation treatment for 24 hour-use.

\section{Materials and Methods}

\subsection{Materials}

DKT (99.8\% purity) was provided by Laboratorios Infarma LTDA (Costa Rica). Chitosan (MW: 100000-300000), polyvinyl alcohol (PVA) (MW: 89000-98000) and gelatin were purchased from Sigma Aldrich; and citric acid monohydrate and benzoic acid from Merck. Distilled water was obtained from LABIOFAR facilities.

\subsection{Preformulation and Formulation}

Literature research was done to obtain information on the potential excipients and manufacturing process that could be used for developing $25.0 \mathrm{ml}$ units of the thermoresponsive transdermal delivery system to be loaded with $110.9 \pm 5.5 \mathrm{mg}$ of DKT (equivalent to $75 \mathrm{mg}$ of DK). Special attention was paid to possible physicochemical incompatibilities and technological disadvantages. Therefore, the following prototype formulations (table 1) were evaluated throughout the study: 
Table 1. Thermoresponsive scaffolds prototypes for DKT controlled release.

\begin{tabular}{cccc}
\hline Composition (w/v \%) & F1 & F2 & F3 \\
\hline DKT & 0.44 & 0.44 & 0.44 \\
Chitosan & 4 & 4 & 4 \\
Polyvinyl alcohol & - & 2 & - \\
Gelatin & - & - & 4 \\
Citric acid & 5 & 5 & 5 \\
Benzoic acid & 0.2 & 0.2 & 0.2 \\
Distilled water & q.s $25,0 \mathrm{ml}$ & q.s $25,0 \mathrm{ml}$ & q.s $25,0 \mathrm{ml}$ \\
\hline
\end{tabular}

DKT: dexketoprofen trometamol, F1: Formulation 1, F2: Formulation 2, F3: Formulation 3.

Scaffolds were prepared by the solvent casting method. Citric acid was dissolved in distilled water to provide a medium with the desired $\mathrm{pH}$. Then, the solution was heated and maintained at $75{ }^{\circ} \mathrm{C}$ for the entire process. DKT was added with continuous agitation until complete dissolution. Benzoic acid, previously dissolved in a small volume of distilled water, was incorporated as well. Chitosan was slowly and steadily added until complete dissolution, avoiding the formation of lumps. For F2 and F3, the secondary polymer was added as done for chitosan. The formed hydrogel was kept with continuous agitation for 2 hours and then, subjected to ultrasonication for 1 hour to get rid of air bubbles. The formulations were then poured into watch glasses and placed into the oven at $80^{\circ} \mathrm{C}$ for 56 hours to eliminate water. The obtained scaffolds were stored in a desiccator protected from light for 24 hours until their use for compatibility tests, SEM analysis or in vitro release studies.

\subsection{Compatibility tests}

The compatibility between excipients and the active pharmaceutical ingredient (API) was evaluated by analyzing three replicas of each raw material and the formulations presented in table 1. The analyses were performed under thermal and Fourier Transformed Infrared (FT-IR) spectroscopy techniques as explained in the following sections.

\subsubsection{Thermal characterization}

Thermogravimetric (TG) analyses were performed using a TA Instruments Q500, under an inert nitrogen atmosphere with a $90 \mathrm{ml} \cdot \mathrm{min}^{-1}$ sample gas and $10 \mathrm{ml} \cdot \mathrm{min}^{-1}$ of balance gas. A sample of approximately $5 \mathrm{mg}$ was added to a platinum crucible and subjected to analysis in the temperature range from $20-800{ }^{\circ} \mathrm{C}$ with a heating rate of $10^{\circ} \mathrm{C} \cdot \mathrm{min}^{-1}$. Also, Differential Scanning Calorimetry (DSC) was performed using a TA instruments Q200, under an inert nitrogen atmosphere with a $50 \mathrm{ml}^{\mathrm{min}} \mathrm{m}^{-1}$ gas flow. A sample of approximately $6 \mathrm{mg}$ was added to an aluminum capsule and subjected to an initial isotherm at 20 ${ }^{\circ} \mathrm{C}$ for $5 \mathrm{~min}$, and then to a heating rate of $5^{\circ} \mathrm{C} \cdot \mathrm{min}^{-1}$ in the temperature range from $20-350$ ${ }^{\circ} \mathrm{C}$.

\subsubsection{Fourier Transformed Infrared Spectroscopy}

Each sample was analyzed using the transmission technique in a Thermo Scientific Nicolet 6700 model in the range $500-4000 \mathrm{~cm}^{-1}$, with 200 scans per sample. Room conditions were maintained at $25{ }^{\circ} \mathrm{C}$ and $30 \%$ relative humidity.

\subsection{Microscopic characterization}

The samples of F1, F2 and F3 scaffolds were metalized with a thin layer of gold by sputtering, with an exposure time of $3 \mathrm{~min}$ at $20 \mathrm{~mA}$. The analyses were performed by a scanning electron microscope of the JSM-6390LV, Jeol, using an acceleration voltage of 5 $\mathrm{kV}$ and spot size of 60 . 


\subsection{In vitro Release studies}

The release profile was initially evaluated to 6 units of F1 scaffold prototype, then to 6 units of F2, and finally to F3 units. The study was done according to USP 42 general chapter $\langle 724\rangle$ Drug Release, using Transdermal Sandwich ${ }^{\mathrm{TM}}$ devices (Hanson Research Corp), VARIAN dissolution equipment VK 7010 with automatic sampling, and apparatus II USP (paddles) at $50 \mathrm{rpm}$ distanced by $25 \pm 2 \mathrm{~mm}$ from the release device surface. Sink conditions were achieved by using $900.00 \mathrm{ml}$ of distilled water at $32 \pm 0.5^{\circ} \mathrm{C}$ as the medium and adjusted to $\mathrm{pH}$ 6.8. A $10.00 \mathrm{ml}$ aliquot from each vessel was taken at 1, 3, 6, 12, 18 and 24 hours (volume was not replaced). A $2.00 \mathrm{ml}$ aliquot from each $10.00 \mathrm{ml}$ sample was taken and diluted in a $10.00 \mathrm{ml}$ volumetric flask. Samples were analyzed using a Thermo Fisher UV-Vis spectrophotometer AQUAMATE at $260 \mathrm{~nm}$. According to Lambert-Beer's law, a calibration curve was performed using five standard solutions of 2.96, 8.89, 14.82, 20.74 and $26.67 \mu \mathrm{g} \cdot \mathrm{ml}^{-1}$ to obtain the following equation $\left(\mathrm{R}^{2}=0.9999\right)$ :

$$
\text { Absorbance }=(0.04452 \pm 0.00031) * \text { Concentration }\left(\frac{\mu \mathrm{g}}{\mathrm{ml}}\right)-(0.0297 \pm 0.0053)
$$

Sample concentration was calculated by substituting the absorbance of the diluted solution in the calibration curve and using a dilution factor of 5 . The released $\mathrm{mg}$ of DKT were obtained by using the sample's concentration and the remaining volume at each time. By taking into account the drug's loaded dose in each unit, it was possible to calculate the average released percentage for the three prototypes over 24 hours. The scaffold prototype that exhibited: a) the best performance in terms of controlled release, b) the major reduction regarding burst release, and c) no physicochemical incompatibility, was selected for further studies to 6 new units following the previously described method, but using the medium at $38 \pm 0.5^{\circ} \mathrm{C}$.

\subsection{Kinetic release models}

Data from the selected prototype were adjusted to zero order, first order, HixsonCrowell, Higuchi, and Korsmeyer-Peppas kinetic models to obtain the release rate at 32 ${ }^{\circ} \mathrm{C}$ and $38{ }^{\circ} \mathrm{C}$. The best models were considered to have the highest $\mathrm{R}^{2}$ and the lowest Akaike information criterion (AIC), which takes into consideration the residual sum of squares (RSS), number of parameters (p) and the number of observations (n) as follows:

$$
\mathrm{AIC}=\mathrm{n} * \ln (\mathrm{SSR})+2 \mathrm{p}
$$

\section{Results and Discussion}

\subsection{Preformulation and Formulation}

Chitosan was chosen as the main polymer of the prototypes due to its outstanding properties for wound healing such as low toxicity, biocompatibility, biodegradability and antimicrobial activity $[17,18]$. The polymer is soluble in aqueous solutions of organic acids, such as citric acid at $\mathrm{pH} 1-4$ due to its primary amino group [19]. All developed prototypes in the hydrogel form presented a $\mathrm{pH}$ within the intended 3.0-3.5 range to guarantee chitosan dissolution. However, its incorporation into the formulations represented a challenge in terms of solubility since it requires a different $\mathrm{pH}$ compared to the involved API and its concentration. DKT is a weak acid salt, and the $\mathrm{pH}$ value of precipitation $(\mathrm{pHp})$ for this substance in the formulations (i.e., the lowest possible $\mathrm{pH}$ where the API is still ionized) is 6.12. As a result, a lower $\mathrm{pH}$ can cause the precipitation of the API as DK, the lipophilic-weak acid [13].

This technological issue was addressed by heating the solution at $75{ }^{\circ} \mathrm{C}$, which allowed dissolving the DKT at a starting $\mathrm{pH}$ of 2.5 at which chitosan is soluble. The initial colloidal solution propitiated the formation of bushy polymeric structures, which combined with chitosan high water absorption, allowed trapping the drug within the 
macroscopic network, and thus, preventing its precipitation [20]. Fig. 1 shows the obtained scaffolds after ultrasonication and dehydration. These prototypes have $7.8 \mathrm{~cm}$ of diameter, presented an amber color, a flexible but not elastic consistency, and exhibited adhesiveness upon contact to fluids, which is relevant for the desired therapeutic outcome.
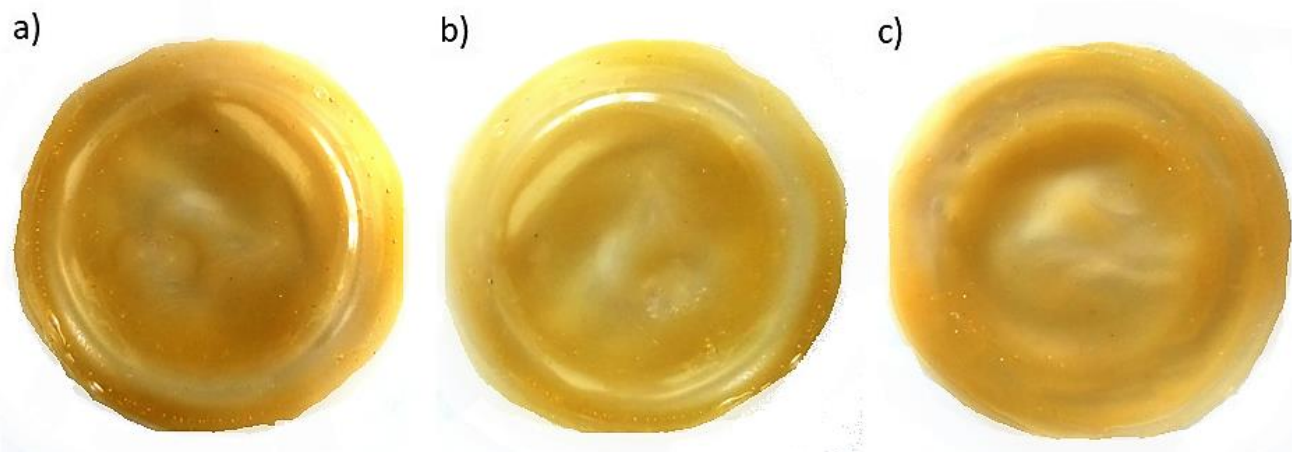

Figure 1. Thermoresponsive scaffold prototypes for DKT controlled release: (a) F1; (b) F2; (c) F3.

\subsection{Compatibility tests}

As can be seen in Fig. 2 ( $a$ and b), it is not possible to identify DKT melting point in the formulations at $107.33^{\circ} \mathrm{C}$ as obtained in the DSC analysis for the raw material due to its low concentration. In addition, polymerization phenomena due to the agitation and heating time could have caused a series of shifts in different thermal events from the constituent materials [21,22]. As a result, it is not possible to appreciate chitosan's endotherm at $90.28{ }^{\circ} \mathrm{C}$ or close in any of the formulations. Also, all scaffolds show a shift in chitosan exotherm at $305.36{ }^{\circ} \mathrm{C}$ to $340-350{ }^{\circ} \mathrm{C}$.

F1 (Fig. 2b) shows a crystalline endotherm at $156.45^{\circ} \mathrm{C}$ that seems to correspond with citric acid melting point $\left(154.11^{\circ} \mathrm{C}\right)$. On the other hand, F2 shows a shift in PVA endotherm at $194.30^{\circ} \mathrm{C}$ to $177.06^{\circ} \mathrm{C}$, which can be due to the polymerization process and crosslinking with citric acid [22]. However, in this formulation, it is not possible to see PVA second endotherm at $323.61{ }^{\circ} \mathrm{C}$ or any other related to chitosan and citric acid. Furthermore, F3 exhibits at $53.56{ }^{\circ} \mathrm{C}$ a small endotherm that can be linked to citric acid first endotherm $\left(57.84^{\circ} \mathrm{C}\right)$, and another one at $174.31^{\circ} \mathrm{C}$ that can be a shift from gelatin's endotherm at $223.81^{\circ} \mathrm{C}$.

Regarding TG (Fig 2. c and d), all the formulas exhibited a thermal degradation behavior related to their constituent materials without showing or suggesting any physicochemical incompatibility between them. Likewise, the scaffolds also showed increased thermal stability due to crosslinking [23]. At $219.03{ }^{\circ} \mathrm{C}, \mathrm{F} 1$ had lost more than $30 \%$ of its weight mainly due to the decomposition of citric acid around $210.18{ }^{\circ} \mathrm{C}$. In addition, at $351.41{ }^{\circ} \mathrm{C}$ the sample weight was reduced up to $40 \%$, which is explained by the decomposition of more than $50 \%$ of the chitosan. F2 shows the same explained degradation behavior, presenting thermal degradation events at $227.45^{\circ} \mathrm{C}$ and $331.51{ }^{\circ} \mathrm{C}$. However, for the signal around $406.50{ }^{\circ} \mathrm{C}$, it is important to mention that the sample has only a $36.16 \%$ of its initial mass, which is due to a great decomposition of PVA. F3 also showed the mentioned behavior regarding the first two main events, but at $335.34{ }^{\circ} \mathrm{C}$ it had only $50.98 \%$ of its mass due to gelatin decomposition at $308.56{ }^{\circ} \mathrm{C}$. 

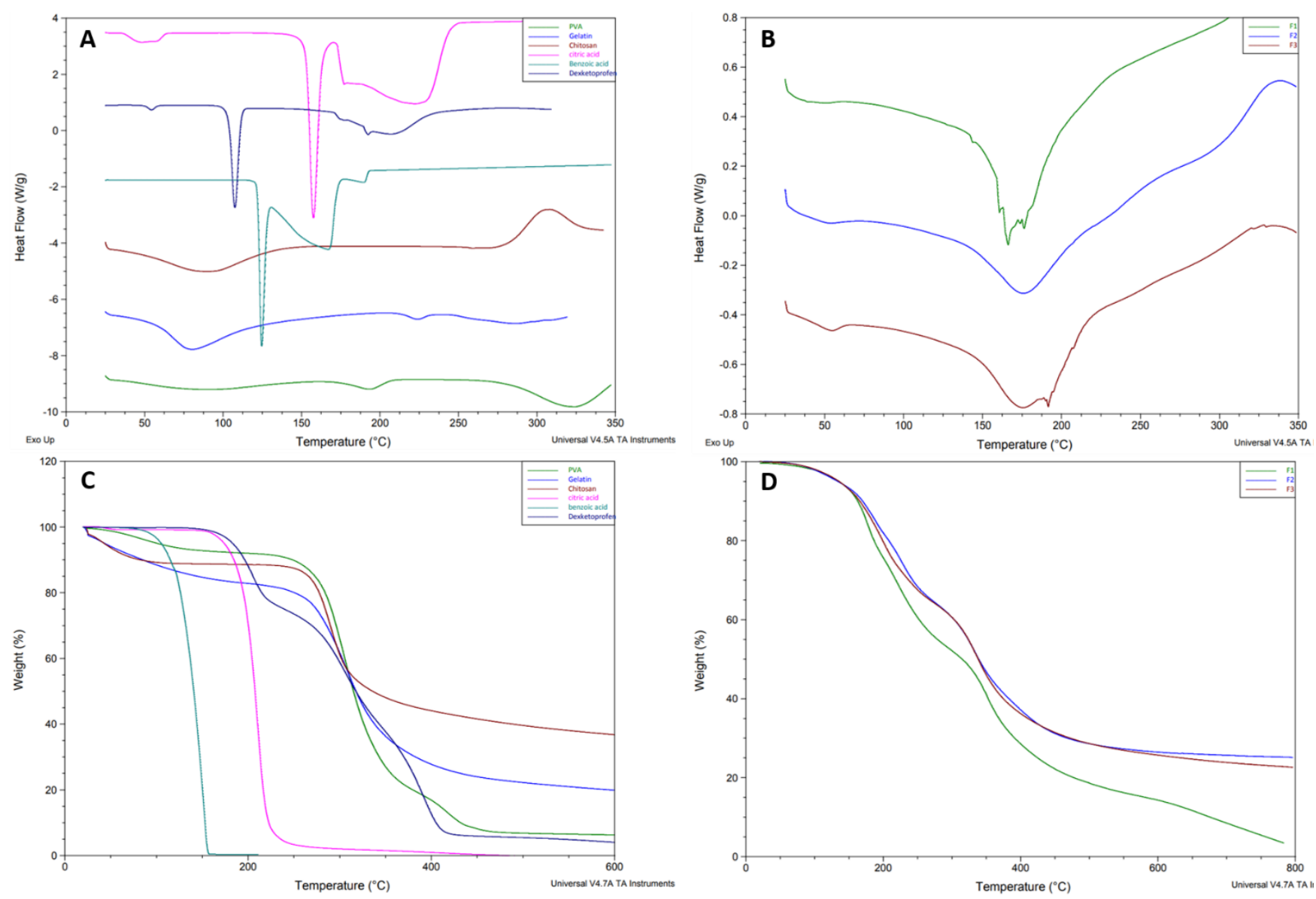

Figure 2. Thermal Analysis; (a) DSC analysis of raw materials: Chitosan (wine), PVA (green), Gelatin (blue), DKT (dark blue), Citric acid (fuchsia) and Benzoic acid (aqua); (b) DSC analysis of the formulation prototypes: F1 (green), F2 (blue), F3 (wine); (c) TG analysis of raw materials: Chitosan (wine), PVA (green), Gelatin (blue), DKT (dark blue), Citric acid (fuchsia) and Benzoic acid (aqua); (d) TG analysis of the formulation prototypes: F1 (green), F2 (blue), F3 (wine).

Likewise, FTIR evaluation (Fig. 3) supports the obtained results by the thermal analysis. In the near IR region, DK strong bands are seen in the three formulations around $1060 \mathrm{~cm}^{-1}$ with vibrations at 1568, 1538 and $771 \mathrm{~cm}^{-1}$, which are also indicative of the raw material purity [24]. Chitosan's O-H stretching close to $3300 \mathrm{~cm}^{-1}$ and the $\mathrm{C}-\mathrm{H}$ vibrations close to $2900 \mathrm{~cm}^{-1}$ are observed in the three formulations [25,26]. Regarding F2, C-H alkyl stretching of PVA can be observed near $2900 \mathrm{~cm}^{-1}$, and also, its typical broad band at 3000$3500 \mathrm{~cm}^{-1}$ [27]. On the other hand, F3 conserves gelatin's characteristic bands of the amide group close to 3434, 1600 and $1550 \mathrm{~cm}^{-1}$, and the asymmetric stretching vibrations are represented with bands between $2950-2800 \mathrm{~cm}^{-1}$ [28]. It is important to emphasize that $\mathrm{F} 3$ is the one that preserves best the bands of the raw materials used. However, all formulations showed a decrease in the vibration peak of the O-H stretch $\left(3000-3500 \mathrm{~cm}^{-1}\right)$ related to the reduced number of $\mathrm{O}-\mathrm{H}$ bonds due to crosslinking [27]. 
a)

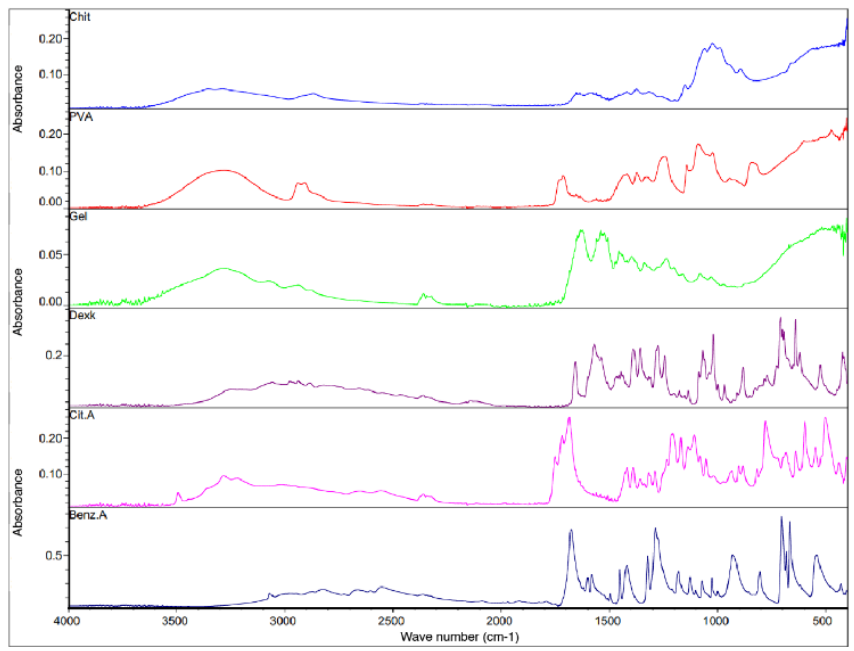

b)

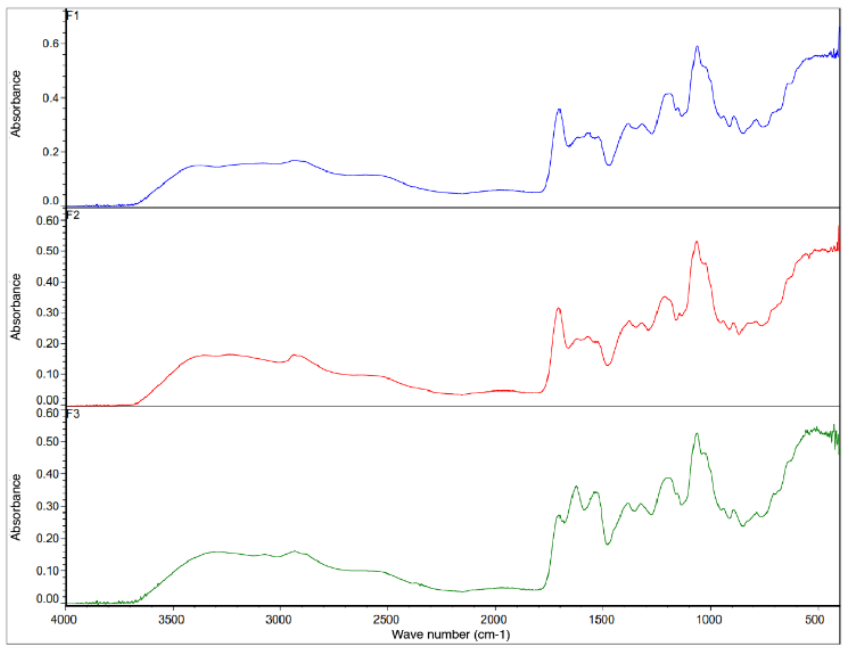

Figure 3. FT-IR spectroscopic analysis; (a) Raw materials: Chitosan (blue), PVA (red), Gelatin (green), DKT (purple), Citric acid (fuchsia) and Benzoic acid (blue); (b) Formulation prototypes: F1 (blue), F2 (red), F3 (green).

\subsection{Scanning Electron Microscopy characterization}

As can be seen in Fig. 4 (a, b, and c), the surface of the three scaffold samples presents a relatively smooth morphology, however, scaffold 1 (Fig. 4a) showed bubbles on the surface with diameters in the range $5 \sim 10 \mu \mathrm{m}$, possibly due to small variations in the drying process and lower efficiency of the ultrasonication process for that formulation. Likewise, the addition of polyvinyl alcohol (Fig. 4e) and gelatin (Fig. 4f) in the formulations leads to changes in the morphology of the scaffold observed by the cross section.
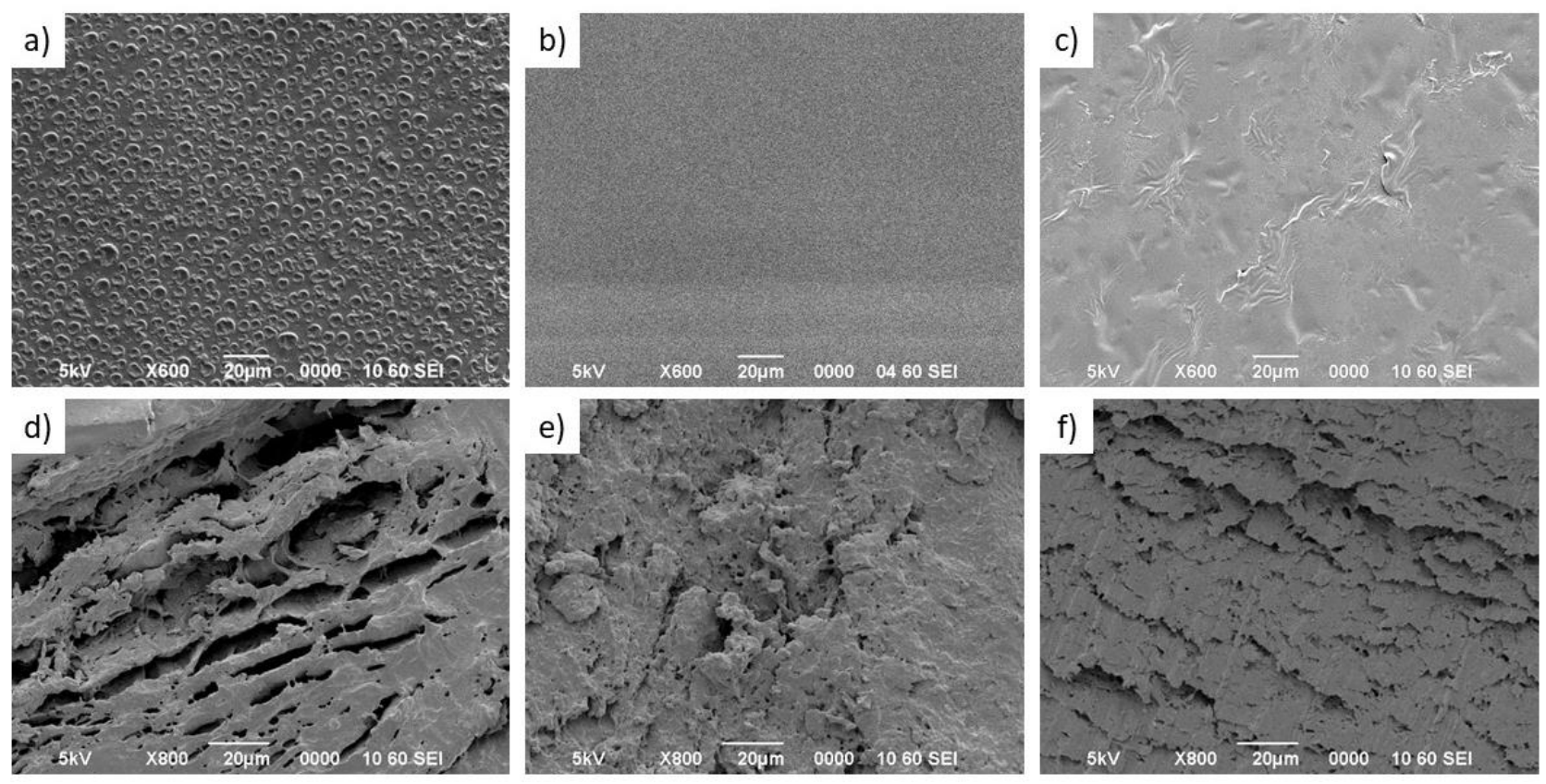

Figure 4. SEM micrographs of the surface $(a, b$ and $c)$ and cross sections ( $d$, e and $f$ ) of three formulated scaffolds (scale bar: $20 \mu \mathrm{m})$; (a, d) F1 scaffold, (b, e) F2 scaffold and (c, f) F3 scaffold.

F1 scaffold (Fig. 4d) has an interconnected network and spaces with cave aspects that can exceed $40 \mu \mathrm{m}$ in length, very different from that observed in F2 scaffold (Fig. 4e) that has a structure like a sponge with the presence of micropores and greater roughness. Furthermore, comparing F1 and F2 with the F3 scaffold (Fig. 4f) that contains gelatin, it is 
possible to identify that this formulation favored the formation of lamellar structures, composed of multiple thin layers arranged in a parallel and compact way. This last morphology could favor a slow release and a reduction of the bursting effect (i.e., an initial large drug bolus released before the stabilization of the release rate) [29].

\subsection{In vitro Release studies}

As mentioned before, chitosan exhibits a LCST of around $32{ }^{\circ} \mathrm{C}$, which is considered to be skin normothermia. As a result, drug release below or at LCST depends on surface desorption, swelling and degradation of the chitosan polymer matrix [30]. As can be seen in Fig. 5a, F1 exhibited the fastest release of all prototypes at $32{ }^{\circ} \mathrm{C}$, reaching an $88.40 \pm$ $5.79 \%$ at 12 hours and $102.18 \pm 1.39 \%$ at 24 hours. Nevertheless, this formulation did not show a controlled release, instead, burst release is notable from the first hour $(31.62 \pm 2.17$ $\%)$ until 6 hours $(75.13 \pm 4.18 \%)$. Although burst release can be optimal in wound healing for immediate relief, the high burst from this formulation cannot provide the prolongedrelease that is required for gradual healing, as well as reduces the lifetime of the scaffold [31,32].

a)

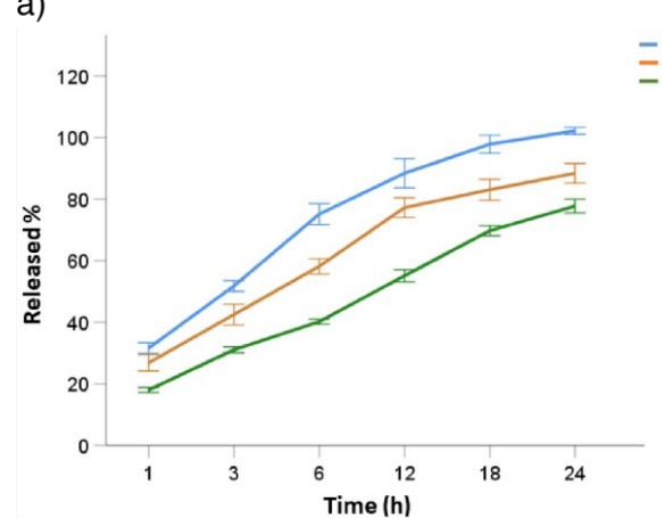

b)

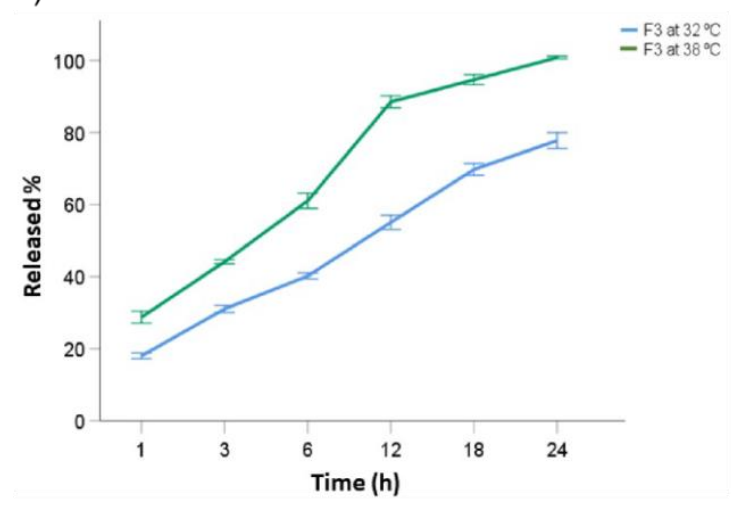

Figure 5. Drug release profile from the scaffolds' prototypes: (a) Average released percentage comparison between the three prototypes at $32{ }^{\circ} \mathrm{C}: \mathrm{F} 1$ (blue), F2 (red), F3 (green); (b) Comparison of the released percentage from F3 at $32{ }^{\circ} \mathrm{C}$ (blue) and $38^{\circ} \mathrm{C}$ (green).

Due to the previous, we evaluated the impact caused by the presence of PVA and gelatin on DKT release from the chitosan-based scaffolds. These polymers were expected to physically crosslink during the manufacturing process to yield a hydrogel, providing the scaffolds with high drug loading capability to control the release [33,34]. F2 (Fig. 5.a) showed a reduction in the drug released at 24 hours $(88.40 \pm 3.94 \%)$ but also reduced burst release compared to $\mathrm{F} 1$ ( $1 \mathrm{~h}: 26,81 \pm 3.25 \%$, $6 \mathrm{~h}: 58.16 \pm 3.07 \%)$. This profile can be attributed to the presence of intra- and inter-crosslinked PVA tubules by the citric acid, which reduce porosity, difficult the penetration of water molecules and reduce wettability [22].

Nonetheless, F3 (Fig. 5.a) was the formulation with the best performance in terms of controlled release and reduction of the burst release. This scaffold was able to reduce the initial burst up to $18.01 \pm 0.99 \%$ in the first hour and $40.18 \pm 1.00 \%$ at 6 hours. In addition, at 12 hours, it delivered a bit more than half of the loaded drug $(55.07 \pm 2.43 \%)$ and a total of $77.75 \pm 2.72 \%$ at 24 hours, approximately equal to $59 \mathrm{mg}$ of DK. The previous release behavior is related to gelatin presence in the scaffold, which causes physical entrapment and absorption of the API. Initially, gelatin provides a release mostly by diffusion, while the following hours are dominated by its degradation, erosion and dissolution [35].

Since F3 provided the best performance, 6 more units were employed for further studies at $38{ }^{\circ} \mathrm{C}$ to simulate the local hyperthermia conditions caused by the typical inflammatory process presented in wound healing [36]. It is well known that thermo-responsive polymers like chitosan, experience a reversible transition under an entropy- 
driven process, from a hydrophilic to a hydrophobic state upon a rise in the temperature above the LCST $[37,38]$. The interruption in polymer-water hydrogen bonding and the increase in hydrophobic interactions within the polymer chains caused the collapse of the structure and the consequent greater burst release compared to the analyzed units of the same formula at $32{ }^{\circ} \mathrm{C}$ (1h: $28.74 \pm 2.06 \%$, 6h: $61.05 \pm 2.59 \%$ ) (Fig. 5.b) [39]. Furthermore, it is important to notice that this initial burst is still lower than the one exhibited by F1 at $32{ }^{\circ} \mathrm{C}$, which can be attributed to the presence of gelatin as well.

\subsection{Kinetic release models}

Rational development of controlled release forms involves in vitro release tests to predict the impact on the in vivo performance of the formulation [40]. $\mathrm{R}^{2}$ and AIC are two relevant values that can be used to evaluate how well a set of models fit. The first one quantifies the intensity of the linear relationship between two variables under study, while the second one is a statistical measure for time series models [41]. Table 2 summarizes the most important results from the kinetic release study for F3. For data obtained at $32{ }^{\circ} \mathrm{C}$ the fitting to the models was made using all sampled times $(\mathrm{n}=6)$, while at $38^{\circ} \mathrm{C}$ only data until 12 hours were used $(n=4)$ because the scaffolds had released more than $85 \%$ of the loaded drug by that time, which is enough for making predictions regarding DKT release upon hyperthermia conditions. Regardless of that, Hixson-Crowell and Korsmeyer-Peppas possessed high values for the $\mathrm{R}^{2}$ and the lowest values for the AIC at both temperatures for which these can be considered as the best fit models.

Table 2. Kinetic release models for $\mathrm{F} 3$ at $32{ }^{\circ} \mathrm{C}$ during 24 hours and at $38^{\circ} \mathrm{C}$ during 12 hours.

\begin{tabular}{|c|c|c|c|c|c|c|}
\hline \multirow{2}{*}{ Model } & \multicolumn{3}{|c|}{$32{ }^{\circ} \mathrm{C}$} & \multicolumn{3}{|c|}{$38^{\circ} \mathrm{C}$} \\
\hline & Release rate constant & $\mathbf{R}^{2}$ & AIC & Release rate constant & $\mathbf{R}^{2}$ & AIC \\
\hline Zero order & $2.70 \pm 0.25 \mathrm{mg} \cdot \mathrm{h}^{-1}$ & 0.9661 & 29.81 & $5.70 \pm 0.43 \mathrm{mg} \cdot \mathrm{h}^{-1}$ & 0.9886 & 15.00 \\
\hline First order & $0.0557 \pm 0.0016 \mathrm{~h}^{-1}$ & 0.9968 & -29.01 & $0.167 \pm 0.016 \mathrm{~h}^{-1}$ & 0.9827 & -9.53 \\
\hline Hixson-Crowell & $\begin{array}{c}0.0669 \pm 0.0028 \\
\mathrm{mg}^{1 / 3} \cdot \mathrm{h}^{-1}\end{array}$ & 0.9931 & -24.18 & $\begin{array}{c}0.1759 \pm 0.0074 \\
\mathrm{mg}^{1 / 3} \cdot \mathrm{h}^{-1}\end{array}$ & 0.9965 & -17.52 \\
\hline Higuchi & $16.51 \pm 0.41 h^{0.5}$ & 0.9976 & 14.08 & $26.1 \pm 1.1 h^{0.5}$ & 0.9965 & 10.34 \\
\hline Korsmeyer-Peppas & $0.181 \pm 0.023 h^{0.457-1}$ & 0.9979 & -32.48 & $0.279 \pm 0.040 h^{0.450-1}$ & 0.9941 & -20.06 \\
\hline
\end{tabular}

Hixson-Crowell's model states that agitation does not affect dissolution rate, which is said to be the controlling factor for the release of the drug instead of its diffusion through the polymer matrix. Although the model considers that dissolution of the matrix causes a surface reduction it requires the original geometric form of the units to persist [42]. However, Korsmeyer-Peppas (Fig. 6) seems to be a better model to explain the release profile from the F3 prototype since it has been widely used for describing the release from polymer systems. In addition, it allows explaining the release mechanism where matrix erosion or dissolution takes place. In this case, the Korsmeyer release rate constant (KКP) is associated with the diffusional exponent (n) from the following equation, where $\mathrm{M}_{\mathrm{t}} / \mathrm{M}_{\infty}$ represents the fraction of drug released at a certain time $(\mathrm{t})$ [43]:

$$
\frac{\mathrm{M}_{\mathrm{t}}}{\mathrm{M}_{\infty}}=\mathrm{K}_{\mathrm{KP}}+\mathrm{t}^{\mathrm{n}}
$$




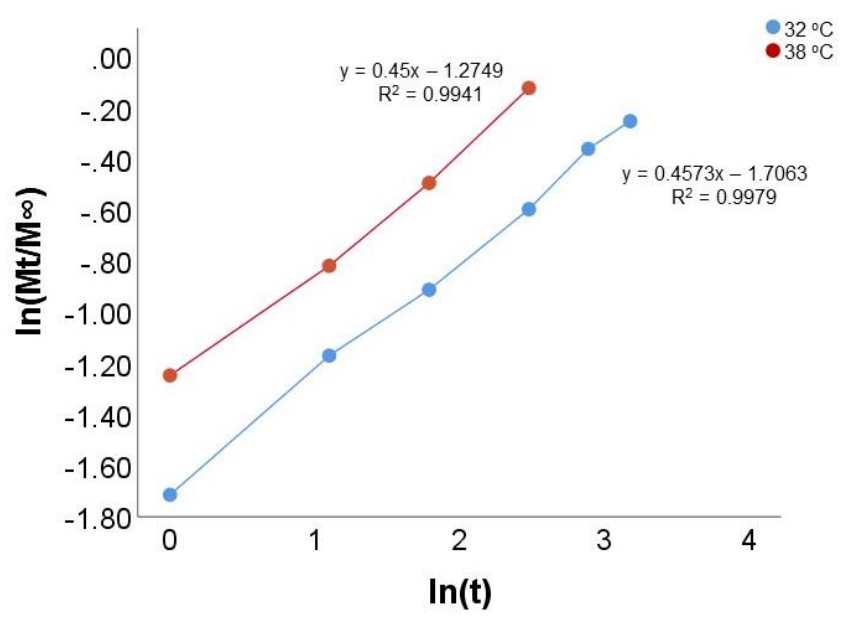

Figure 6. Fitted release data to Korsmeyer-Peppas kinetic model at $32{ }^{\circ} \mathrm{C}$ (blue) and $38^{\circ} \mathrm{C}$ (red).

The obtained values for the exponent $\mathrm{n}$ at $32{ }^{\circ} \mathrm{C}$ and $38^{\circ} \mathrm{C}$ were respectively 0.457 and 0.450 , which represent a non-Fickian transport mechanism and a diffusion-swelling controlled process $\left(\mathrm{KKP}_{\mathrm{KP}}=\mathrm{h}^{\mathrm{n}-1}\right)$. The previous is due to the presence of small pores filled with the dissolution medium in the polymer matrix, allowing the subsequent diffusion of DKT through the swelled structure [43]. On the other hand, the first-order model seems to fit only at $32{ }^{\circ} \mathrm{C}$. This model is used for describing drug release from porous structures and it is conditioned by the saturation point of the drug in the medium. Nevertheless, it could not fit the profile at $38^{\circ} \mathrm{C}$ since the model is not capable of adjusting the initial data at a higher release rate [42].

\section{Conclusions}

The developed chitosan-based scaffold performance is influenced by the constituent polymers, such as gelatin, which allows a sustained release and the reduction of the initial burst. In addition, the natural feedback from the host expressed as local hyperthermia can modify the release of the loaded drug as well. As a result, this scaffold can be used to deliver the necessary dose according to each patient in order to provide the therapeutic effect. Thus, it can be considered as a suitable system for wound healing with a controlled release of DKT for 24 hour-use that can also potentially reduce side effects, allowing overcoming adherence issues and wound healing complications. However, further studies are recommended to evaluate in vivo cell proliferation, as well as the allergenic potential that may affect sensitized individuals to seafood due to chitosan synthesis from crustacean shells.

Author Contributions: Conceptualization, L.C.H., N.R.A., and J.V.B; methodology, L.C.H., P.S.E., B.C.G., and J.V.B.; formal analysis, L.C.H., G.M.O., B.M.C., and D.B.M.; investigation, L.C.H., P.S.E., G.M.O., B.M.C., and D.B.M.; resources, N.R.A., and J.V.B.; writing-original draft preparation, L.C.H., G.M.O., B.M.C., and D.B.M.; writing-review and editing, L.C.H., G.M.O., and D.B.M.; visualization, G.M.O., and D.B.M.; supervision, N.R.A., and J.V.B., project administration, J.V.B. All authors have read and agreed to the published version of the manuscript.

Funding: First author, L.C.H., is a funded student by the Education, Audiovisual and Culture Executive Agency (EACEA) of the European Commission in the field of the Erasmus Mundus Joint Master Degree (EMJMD) of Nanomedicine for Drug Delivery (NANOMED).

Acknowledgments: This paper represents a collaborative work between LANOTEC-CeNATCONARE, and the LABIOFAR-INIFAR-University of Costa Rica in commemoration of the $17^{\text {th }}$ anniversary of LANOTEC and the $15^{\text {th }}$ anniversary of LABIOFAR. The authors would also like to thank Gabriel Jiménez Thuel for contributing to the figures and graphical abstract design.

Conflicts of Interest: The authors declare no conflict of interest. 


\section{References}

1. Shukla, S.K.; Sharma, A.K.; Gupta, V.; Yashavarddhan, M.H. Pharmacological Control of Inflammation in Wound Healing. Journal of Tissue Viability 2019, 28, 218-222, doi:10.1016/j.jtv.2019.09.002.

2. Ellis, S.; Lin, E.J.; Tartar, D. Immunology of Wound Healing. Curr Derm Rep 2018, 7, 350-358, doi:10.1007/s13671-018-0234-9.

3. Sahana, T.G.; Rekha, P.D. Biopolymers: Applications in Wound Healing and Skin Tissue Engineering. Mol Biol Rep 2018, 45, 2857-2867, doi:10.1007/s11033-018-4296-3.

4. Rodrigues, M.; Kosaric, N.; Bonham, C.A.; Gurtner, G.C. Wound Healing: A Cellular Perspective. Physiological Reviews 2019, 99, 665-706, doi:10.1152/physrev.00067.2017.

5. O’Brien, F.J. Biomaterials \& Scaffolds for Tissue Engineering. Materials Today 2011, 14, 88-95, doi:10.1016/S1369-7021(11)70058$X$.

6. Singh, B.N.; Panda, N.N.; Mund, R.; Pramanik, K. Carboxymethyl Cellulose Enables Silk Fibroin Nanofibrous Scaffold with Enhanced Biomimetic Potential for Bone Tissue Engineering Application. Carbohydrate Polymers 2016, 151, 335-347, doi:10.1016/j.carbpol.2016.05.088.

7. Calori, I.R.; Braga, G.; de Jesus, P. da C.C.; Bi, H.; Tedesco, A.C. Polymer Scaffolds as Drug Delivery Systems. European Polymer Journal 2020, 129, 109621, doi:10.1016/j.eurpolymj.2020.109621.

8. Negut, I.; Dorcioman, G.; Grumezescu, V. Scaffolds for Wound Healing Applications. Polymers 2020, 12, 2010, doi:10.3390/polym12092010.

9. Doberenz, F.; Zeng, K.; Willems, C.; Zhang, K.; Groth, T. Thermoresponsive Polymers and Their Biomedical Application in Tissue Engineering - a Review. J. Mater. Chem. B 2020, 8, 607-628, doi:10.1039/C9TB02052G.

10. Argüelles-Monal, W.; Recillas-Mota, M.; Fernández-Quiroz, D. Chitosan-Based Thermosensitive Materials; IntechOpen, 2017; ISBN 978-953-51-2860-1.

11. Liu, H.; Wang, C.; Li, C.; Qin, Y.; Wang, Z.; Yang, F.; Li, Z.; Wang, J. A Functional Chitosan-Based Hydrogel as a Wound Dressing and Drug Delivery System in the Treatment of Wound Healing. RSC Advances 2018, 8, 7533-7549, doi:10.1039/C7RA13510F.

12. Haley, R.M.; von Recum, H.A. Localized and Targeted Delivery of NSAIDs for Treatment of Inflammation: A Review. Exp Biol Med (Maywood) 2019, 244, 433-444, doi:10.1177/1535370218787770.

13. Bermejo, M.; Kuminek, G.; Al-Gousous, J.; Ruiz-Picazo, A.; Tsume, Y.; Garcia-Arieta, A.; González-Alvarez, I.; Hens, B.; Mudie, D.; Amidon, G.E.; et al. Exploring Bioequivalence of Dexketoprofen Trometamol Drug Products with the Gastrointestinal Simulator (GIS) and Precipitation Pathways Analyses. Pharmaceutics 2019, 11, 122, doi:10.3390/pharmaceutics11030122.

14. Mititelu-Tartau, L.; Bogdan, M.; Pricop, D.A.; Buca, B.R.; Hilitanu, L.; Pauna, A.-M.; Dijmarescu, L.A.; Popa, E.G. Biocompatibility and Pharmacological Effects of Innovative Systems for Prolonged Drug Release Containing Dexketoprofen in Rats. Polymers 2021, 13, 1010, doi:10.3390/polym13071010.

15. Öztürk, A.A.; Kıyan, H.T. Treatment of Oxidative Stress-Induced Pain and Inflammation with Dexketoprofen Trometamol Loaded Different Molecular Weight Chitosan Nanoparticles: Formulation, Characterization and Anti-Inflammatory Activity by Using in Vivo HET-CAM Assay. Microvascular Research 2020, 128, 103961, doi:10.1016/j.mvr.2019.103961.

16. Çulcu, Ö.; Tunçel, E.; Tamer, S.İ; Tirnaksiz, F.F. Characterization of Thermosensitive Gels for the Sustained Delivery of Dexketoprofen Trometamol for Dermal Applications. Journal of Gazi University Health Sciences Institute 2020, 2, 1-12.

17. Moeini, A.; Cimmino, A.; Dal Poggetto, G.; Di Biase, M.; Evidente, A.; Masi, M.; Lavermicocca, P.; Valerio, F.; Leone, A.; Santagata, G.; et al. Effect of PH and TPP Concentration on Chemico-Physical Properties, Release Kinetics and Antifungal Activity of Chitosan-TPP-Ungeremine Microbeads. Carbohydrate Polymers 2018, 195, 631-641, doi:10.1016/j.carbpol.2018.05.005.

18. Intini, C.; Elviri, L.; Cabral, J.; Mros, S.; Bergonzi, C.; Bianchera, A.; Flammini, L.; Govoni, P.; Barocelli, E.; Bettini, R.; et al. 3DPrinted Chitosan-Based Scaffolds: An in Vitro Study of Human Skin Cell Growth and an in-Vivo Wound Healing Evaluation in Experimental Diabetes in Rats. Carbohydrate Polymers 2018, 199, 593-602, doi:10.1016/j.carbpol.2018.07.057. 
19. Rowe, R.C.; Sheskey, P.; Quinn, M. Handbook of Pharmaceutical excipients; Libros Digitales - Pharmaceutical Press, 2009; ISBN 978$1-58212-135-2$.

20. Chang, Z.; Chen, Y.; Tang, S.; Yang, J.; Chen, Y.; Chen, S.; Li, P.; Yang, Z. Construction of Chitosan/Polyacrylate/Graphene Oxide Composite Physical Hydrogel by Semi-Dissolution/Acidification/Sol-Gel Transition Method and Its Simultaneous Cationic and Anionic Dye Adsorption Properties. Carbohydrate Polymers 2020, 229, 115431, doi:10.1016/j.carbpol.2019.115431.

21. Wesolowski, M.; Rojek, B. Thermogravimetric Detection of Incompatibilities between Atenolol and Excipients Using Multivariate Techniques. J Therm Anal Calorim 2013, 113, 169-177, doi:10.1007/s10973-013-3070-y.

22. Flores-Arriaga, J.C.; Chavarría-Bolaños, D.; Pozos-Guillén, A. de J.; Escobar-Barrios, V.A.; Cerda-Cristerna, B.I. Synthesis of a PVA Drug Delivery System for Controlled Release of a Tramadol-Dexketoprofen Combination. J Mater Sci: Mater Med 2021, 32, 56, doi:10.1007/s10856-021-06529-3.

23. Khouri, J.; Penlidis, A.; Moresoli, C. Viscoelastic Properties of Crosslinked Chitosan Films. Processes 2019, 7, 157, doi:10.3390/pr7030157.

24. Öztürk, A.A.; Banderas, L.M.; Otero, M.D.C.; Yenilmez, E.; Şenel, B.; Yazan, Y. Dexketoprofen Trometamol-Loaded Poly-LacticCo-Glycolic Acid (PLGA) Nanoparticles: Preparation, in Vitro Characterization and Cyctotoxity. Tropical Journal of Pharmaceutical Research 2019, 18, 1-11, doi:10.4314/tjpr.v18i1.1.

25. Cusihuamán Noa, S.; Talavera Núñez, M.E.; Arenas Chávez, C.; Pacheco Salazar, D.G.; Vera Gonzales, C. Caracterización Por Técnicas Espectroscópicas Del O-Carboximetilquitosano Obtenido Por Derivatización Del Quitosano. Revista de la Sociedad Química del Perú 2018, 84, 204-216.

26. Pieklarz, K.; Galita, G.; Tylman, M.; Maniukiewicz, W.; Kucharska, E.; Majsterek, I.; Modrzejewska, Z. Physico-Chemical Properties and Biocompatibility of Thermosensitive Chitosan Lactate and Chitosan Chloride Hydrogels Developed for Tissue Engineering Application. Journal of Functional Biomaterials 2021, 12, 37, doi:10.3390/jfb12020037.

27. Reis, E.F. dos; Campos, F.S.; Lage, A.P.; Leite, R.C.; Heneine, L.G.; Vasconcelos, W.L.; Lobato, Z.I.P.; Mansur, H.S. Synthesis and Characterization of Poly (Vinyl Alcohol) Hydrogels and Hybrids for RMPB70 Protein Adsorption. Mat. Res. 2006, 9, 185-191, doi:10.1590/S1516-14392006000200014.

28. Ibrahim, M.; Mahmoud, A.A.; Osman, O.; Abd El-Aal, M.; Eid, M. Molecular Spectroscopic Analyses of Gelatin. Spectrochimica Acta Part A: Molecular and Biomolecular Spectroscopy 2011, 81, 724-729, doi:10.1016/j.saa.2011.07.012.

29. Rajak, P.; Nath, L.K.; Bhuyan, B. Liquid Crystals: An Approach in Drug Delivery. Indian Journal of Pharmaceutical Sciences 2019, 81, 11-21, doi:10.4172/pharmaceutical-sciences.1000474.

30. Zhang, Q.; Weber, C.; Schubert, U.S.; Hoogenboom, R. Thermoresponsive Polymers with Lower Critical Solution Temperature: From Fundamental Aspects and Measuring Techniques to Recommended Turbidimetry Conditions. Mater. Horiz. 2017, 4, 109116, doi:10.1039/C7MH00016B.

31. Cam, M.E.; Yildiz, S.; Alenezi, H.; Cesur, S.; Ozcan, G.S.; Erdemir, G.; Edirisinghe, U.; Akakin, D.; Kuruca, D.S.; Kabasakal, L.; et al. Evaluation of Burst Release and Sustained Release of Pioglitazone-Loaded Fibrous Mats on Diabetic Wound Healing: An in Vitro and in Vivo Comparison Study. Journal of The Royal Society Interface 2020, 17, 20190712, doi:10.1098/rsif.2019.0712.

32. Moeini, A.; Pedram, P.; Makvandi, P.; Malinconico, M.; Gomez d'Ayala, G. Wound Healing and Antimicrobial Effect of Active Secondary Metabolites in Chitosan-Based Wound Dressings: A Review. Carbohydrate Polymers 2020, 233, 115839, doi:10.1016/j.carbpol.2020.115839.

33. Naseri, N.; Algan, C.; Jacobs, V.; John, M.; Oksman, K.; Mathew, A.P. Electrospun Chitosan-Based Nanocomposite Mats Reinforced with Chitin Nanocrystals for Wound Dressing. Carbohydrate Polymers 2014, 109, 7-15, doi:10.1016/j.carbpol.2014.03.031.

34. Martínez-Martínez, M.; Rodríguez-Berna, G.; Bermejo, M.; Gonzalez-Alvarez, I.; Gonzalez-Alvarez, M.; Merino, V. Covalently Crosslinked Organophosphorous Derivatives-Chitosan Hydrogel as a Drug Delivery System for Oral Administration of Camptothecin. European Journal of Pharmaceutics and Biopharmaceutics 2019, 136, 174-183, doi:10.1016/j.ejpb.2019.01.009. 
35. Gentile, P.; Nandagiri, V.K.; Daly, J.; Chiono, V.; Mattu, C.; Tonda-Turo, C.; Ciardelli, G.; Ramtoola, Z. Localised Controlled Release of Simvastatin from Porous Chitosan-Gelatin Scaffolds Engrafted with Simvastatin Loaded PLGA-Microparticles for Bone Tissue Engineering Application. Materials Science and Engineering: C 2016, 59, 249-257, doi:10.1016/j.msec.2015.10.014.

36. Ciaccia, L. Fundamentals of Inflammation. Yale J Biol Med 2011, 84, 64-65.

37. Amado, S.; Morouço, P.; Pascoal-Faria, P.; Alves, N. Tailoring Bioengineered Scaffolds for Regenerative Medicine. Biomaterials in Regenerative Medicine 2017, doi:10.5772/intechopen.69857.

38. Castillo-Henríquez, L.; Castro-Alpízar, J.; Lopretti-Correa, M.; Vega-Baudrit, J. Exploration of Bioengineered Scaffolds Composed of Thermo-Responsive Polymers for Drug Delivery in Wound Healing. International Journal of Molecular Sciences 2021, 22, 1408, doi:10.3390/ijms22031408.

39. Lee, C.H.; Bae, Y.C. Thermodynamic Framework for Switching the Lower Critical Solution Temperature of Thermo-Sensitive Particle Gels in Aqueous Solvent. Polymer 2020, 195, 122428, doi:10.1016/j.polymer.2020.122428.

40. Application of Mathematical Models in Drug Release Kinetics of Carbidopa and Levodopa ER Tablets I Abstract Available online: https://www.longdom.org/abstract/application-of-mathematical-models-in-drug-release-kinetics-of-carbidopa-andlevodopa-er-tablets-16361.html (accessed on 12 September 2021).

41. Portet, S. A Primer on Model Selection Using the Akaike Information Criterion. Infectious Disease Modelling 2020, 5, 111-128, doi:10.1016/j.idm.2019.12.010.

42. Rehman, Q.; Akash, M.S.H.; Rasool, M.F.; Rehman, K. Role of Kinetic Models in Drug Stability. In Drug Stability and Chemical Kinetics; Akash, M.S.H., Rehman, K., Eds.; Springer: Singapore, 2020; pp. 155-165 ISBN 9789811564260.

43. Dima, C.; Pătraşcu, L.; Cantaragiu, A.; Alexe, P.; Dima, Ş. The Kinetics of the Swelling Process and the Release Mechanisms of Coriandrum Sativum L. Essential Oil from Chitosan/Alginate/Inulin Microcapsules. Food Chemistry 2016, 195, 39-48, doi:10.1016/j.foodchem.2015.05.044. 